\title{
Development of a novel Al-Cu-Ti metallic glass reinforced Al matrix composite consolidated through equal channel angular pressing (ECAP)
}

\author{
M.R. Rezaei ${ }^{\text {a }}$, S.H. Razavi ${ }^{\text {b }}$, S.G. Shabestari ${ }^{{ }^{*}}$ \\ ${ }^{a}$ Ph.D. student, School of Metallurgy and Materials Engineering, Iran University of Science and Technology \\ (IUST), Associate Professor ${ }^{b}$, Professor ${ }^{c}$, Center of Excellence for High Strength Alloys Technology (CEHSAT), \\ School of Metallurgy and Materials Engineering, Iran University of Science and Technology (IUST), 16846-13114, \\ Narmak, Tehran, Iran, * Corresponding author: shabestari@iust.ac.ir
}

\begin{abstract}
In this study, the equal channel angular pressing (ECAP) process was used to develop a novel Al matrix composite through consolidation of pure aluminum powder having different volume fractions of $\mathrm{Al}_{65} \mathrm{Cu}_{20} \mathrm{Ti}_{15}$ metallic glass (AMG) as reinforcing particles. The structural evolution and mechanical properties of the composites were investigated. The densities of the samples were measured to evaluate the performance of the consolidation process. Structural analyses showed finely distributed reinforcing particles produced through shearing deformation, imposed during ECAP. Also, amorphous structure of reinforcement remained unchanged during ECAP at all volume fractions. The relative density of $\mathrm{Al} / 10$ vol\% AMG composites was $97.94 \%$ which is the strong evidence for capability of ECAP to produce AMG reinforced Al matrix composites. The compressive yield strength of $184 \mathrm{MPa}$ was obtained in Al/10 vol\% AMG composite which showed a remarkable increase in the strength compared with pure Al. Also, the compressive yield strength of the developed composites has been compared with those estimated through the rule of mixtures.
\end{abstract}

Keywords: A. metal matrix composites, A. metallic glasses; C. microstructure, C. mechanical properties D. scanning electron microscopy, SEM, D. X-ray diffraction. 


\section{Introduction}

Among the advanced engineering materials for aerospace and automotive applications, a growing interest has been shown in developing aluminum matrix composites (AMCs) due to their unique mechanical properties such as lightweight and high elastic modulus and strength [13]. Aluminum is a light and relatively weak metal. Reinforcing the metallic matrix with ceramic particles such as oxides or carbides leads to the improvement in physical and mechanical properties of composites $[4,5]$. However, poor wettability between the composite constituents is often a reason for the porosity localized at the matrix-reinforcement interfaces which results in weak reinforcement-matrix interfacial bonding with reduced mechanical properties and increased corrosion sensitivity [6]. Also, the drastic reduction in ductility which occurs in AMCs due to the inherent brittleness of ceramic reinforcements is critical drawback. Metallic glasses as a novel type of reinforcement have been recently considered to overcome the disadvantages of conventional ceramic reinforcing particles $[7,8]$. The unique properties of the metallic glasses introduced them as new reinforcements for making light metal composites. The metallic glass reinforcements, containing almost metallic elements, are believed to be more compatible with the metal matrix and to result in superior interface bonding than the conventional ceramic reinforcements $[9,10]$. Among metallic glasses, Al-based metallic glasses display unusual properties such as low density, high strength, good ductility, high fracture toughness and good corrosion resistance $[10,11]$ which would make them suitable reinforcements for producing high strength light metal composites. $\mathrm{Al}_{65} \mathrm{Cu}_{20} \mathrm{Ti}_{15}$ alloy as an Al-based metallic glass possess all above mentioned properties besides high content of $\mathrm{Al}$ element which can form strong interfaces with pure Al matrix of composite. Also, similar compositions between glass reinforcement and 
Al matrix may bring the advantage of similar coefficient of thermal expansion which leads to reduction in internal stress and the possibility of propagation of crack.

Several processing routes have been developed to prepare particulate metal matrix composites (MMCs) such as powder metallurgy, casting, spray deposition, etc. [12]. Among these methods, powder metallurgy is the most suitable method for making metal matrix composites with attractive properties $[13,14]$. In this method, the powders are mixed completely and then they are consolidated. Some secondary mechanical procedures such as extrusion are used to improve the metallurgical bonding between particles and promote distribution of reinforcement particles into the composite matrix [15]. However, some of the drawbacks associated with extrusion such as reduction of material cross section and low productivity rate have limited utilization of extrusion as a secondary process on the composites. Recently, severe plastic deformation (SPD) methods have been used to overcome these limitations. One of the promising SPD processes which was used as a consolidation process is ECAP [16-18]. ECAP is a method for subjecting a volume of material to severe shear deformation by forcing it around a corner. Benefits of the ECAP process include: reducing the processing temperature with respect to conventional PM consolidation processes, constant specimen cross-section, uniform deformation throughout the workpiece and consolidation to near full density after a single pass $[19,20]$.

The aim of this research, is to combine the advantages of $\mathrm{Al}_{65} \mathrm{Cu}_{20} \mathrm{Ti}_{15}$ metallic glass (AMG) particles as a reinforcement and equal channel angular pressing (ECAP) as PM consolidation process, in order to produce high strength aluminum matrix composites. The microstructure, consolidation behavior and mechanical properties of the samples, including their compression strength and ductility, were studied. 


\section{Experimental Procedure}

\subsection{Materials preparation}

In the present study, atomized commercially pure aluminum powders were used for a matrix material. For reinforcement particles, a mixture of elemental $\mathrm{Al}, \mathrm{Cu}$, and $\mathrm{Ti}$ powders having at least $99.5 \mathrm{wt} \%$ purity and about $45-100 \mu \mathrm{m}$ particle size were used in appropriate proportion to obtain the nominal stoichiometry of $\mathrm{Al}_{65} \mathrm{Cu}_{20} \mathrm{Ti}_{15}$ and they were subjected to mechanical alloying in a Retsch PM 400 high-energy planetary ball mill under Ar atmosphere. The milling medium was stainless steel balls, $10 \mathrm{~mm}$ in diameter. The ball-to-powder weight ratio (BPR) and rotational speed were 10:1 and $300 \mathrm{rpm}$, respectively. A small amount of stearic acid was added to the containers as process control agent (PCA) in order to overcome the problem of sticking of the powder to the balls and the container wall. Ball milling continued to $30 \mathrm{~h}$ to obtain fully glass Al65Cu20Ti15 particles. Particles size distribution of aluminum powders and produced glass Al65Cu20Ti15 particles was analyzed using SHIMADZU SALD-2300 laser diffraction system by wet dispersion in water.

\subsection{Mechanical Blending}

In order to produce glass-reinforced MMC, aluminum powder was blended with 5, 10 and 15 Vol\% of $\mathrm{Al}_{65} \mathrm{Cu}_{20} \mathrm{Ti}_{15}$ glassy powders in a low energy horizontal ball mill operating at a rotation speed of $100 \mathrm{rpm}$ with a mixing time of $2 \mathrm{~h}$. The ball-to-powder weight ratio (BPR) was set to 1:10. The purpose of this step is to mix powders without changing their original characteristics.

\subsection{Consolidation}

Consolidation of the blended powders was carried out via ECAP. The two channels intersecting at $90^{\circ}$ had the channel diameter of $19.1 \mathrm{~mm}$. The powder to be consolidated was poured into 
copper tube and the ends of tubes were closed with front and rear copper plugs. Dimensions of copper tube filled with powders are shown in Fig. 1. The tubes lubricated with $\mathrm{MoS}_{2}$-based lubricant to reduce friction and placed in the entrance channel. ECAP consolidation temperature was chosen to be $250{ }^{\circ} \mathrm{C}$ which is below the first crystallization onset temperature of glassy reinforcement particles. The variation of temperature was about $\pm 5^{\circ} \mathrm{C}$ and it was measured via a thermocouple near the deformation zone. The pressing speed used was set to $2 \mathrm{~mm} / \mathrm{s}$. After ECAP and removing the copper tubes, the consolidated specimens had a diameter and maximum length of about 14 and $45 \mathrm{~mm}$, respectively.

Fig. 1.

\subsection{Materials characterization}

Densities of the compacted powders were determined through Archimedes procedure according to the standard ASTM B93-13. Theoretical density of the composite samples was calculated based on the mixture rule, and the density of AMG particles was calculated to be $3.80 \mathrm{~g} / \mathrm{cm} 3$ using pycnometer. To investigate the microstructure changes in the materials, the samples were prepared by cutting from the cross-section perpendicular to the axial direction of the ECAP billets. To examine the morphologies of raw materials and produced $\mathrm{Al}_{65} \mathrm{Cu}_{20} \mathrm{Ti}_{15}$ amorphous powders and also the distribution of reinforcements in the matrix of consolidated composites, scanning electron microscopy (SEM) model VEGA-TESCAN equipped with EDX analyzer was used. The determination of the spatial distribution of reinforcement particles in the aluminum matrix was carried out on five SEM images in each composite, so that the number of particles in each micrograph was higher than 400 in all cases. Image analyses were performed using Clemex software. The grain structures of the bulk specimens were also characterized by field-emission 
scanning electron microscopy (FE-SEM, MIRA3-TESCAN) operating at $15 \mathrm{kV}$ with a working distance of $7 \mathrm{~mm}$. For FE-SEM investigations, specimens were mechanically polished and then electropolishing was performed using a 30\% nitric acid and 70\% ethanol solution at $12 \mathrm{~V}$ for 19 s. X-ray diffraction analysis was carried out on both the powder and bulk samples using diffractometer model Jeol-JDX-8030. The samples were exposed continuously to $\mathrm{Cu} \mathrm{K} \alpha$ radiation operated at $30 \mathrm{kV} / 20 \mathrm{~mA}$ for a scanning range of $15-80^{\circ}$ in steps of 0.02 .

\subsection{Mechanical evaluation}

Compression tests were carried out on cylindrical specimens of $8 \mathrm{~mm}$ in diameter and $12 \mathrm{~mm}$ long (aspect ratio $\sim 1.5$ ) at a nominal strain rate of $1.0 \times 10^{-3} \mathrm{~s}^{-1}$ with a Hounsfield H50KS TM tensometer (Tinius Olsen Ltd, Redhill, UK).

\section{Results and discussion}

\subsection{Powders specifications}

Aluminum particles exhibit irregular shape as shown in Fig. 2a. As shown in Fig. 2b, the aluminum powders include a wide size distribution and mean powder particle diameter is $53 \mu \mathrm{m}$.

\section{Fig. 2.}

Fig. 3a shows morphologies of $\mathrm{Al}_{65} \mathrm{Cu}_{20} \mathrm{Ti}_{15}$ powders after $30 \mathrm{~h}$ milling time. As it can be seen, they have irregular shape. EDS analysis was employed to identify the chemical composition of particles. The average chemical composition of the particles, was found to be $\mathrm{Al}: 64.93$ at. $\% \pm 1$, Cu: 20.85 at. $\% \pm 1$ and Ti 13.75 at. $\% \pm 1.5$. Ball milled powders also exhibit a narrow size distribution with mean particle diameter of about $7 \mu \mathrm{m}$ (Fig. 3b). Near equiaxed morphology and narrow size distribution of $\mathrm{Al}_{65} \mathrm{Cu}_{20} \mathrm{Ti}_{15}$ powders indicate that the ball milling process has 
reached its steady state. The final stage of ball milling process called "steady state" in which welding and fracture mechanisms reach equilibrium and thereafter, the particle size and size distribution remain approximately unchanged [21].

Fig. 3.

The morphologies of blended composite powders are shown in Fig. 4. It is obvious that blending has not affected the morphologies of mixed powders and nearly homogeneous blend of matrix and reinforcement particles have been obtained. The low ball-to-powder weight ratio has provided a better blend homogeneity without the risk of morphological changes of the powder particles during mixing.

Fig. 4.

\subsection{Consolidation}

\subsubsection{Characterization}

Fig. 5 shows the XRD patterns of the composites with varying reinforcement volume fractions. The XRD patterns of final milled $\mathrm{Al}_{65} \mathrm{Cu}_{20} \mathrm{Ti}_{15}$ powders and pure $\mathrm{Al}$ powders are also shown in Fig 5. The XRD pattern of milled $\mathrm{Al}_{65} \mathrm{Cu}_{20} \mathrm{Ti}_{15}$ powders shows a broad hump at $35^{\circ} \leq 2 \theta \leq 50^{\circ}$ which is the typical of amorphous materials and without any characteristic peaks. The Al/5 vol.\% AMG composite displays only the diffraction peaks of pure $\mathrm{Al}$ and does not show typical amorphous broad halo diffraction patterns due to the scattering from 5 vol. $\%$ of AMG reinforcement is too weak to be detected. For other composites, the patterns display sharp Bragg peaks of pure $\mathrm{Al}$, together with the broad amorphous halo and absence of any secondary phase. This indicates that no crystallization of the glassy material occurred during consolidation. Also, no reaction products have been formed between the pure Al matrix and the glassy reinforcement. 
This is another advantage of glassy reinforcement with respect to conventional ceramic reinforcements. In conventional ceramic reinforced composites, reaction products form due to matrix-particle interaction and impose adverse effects on the mechanical properties [22]. A slight displacement of amorphous halo peak towards higher angles can be seen for Al/10 vol.\% AMG and Al/15 vol.\% AMG composites. Shear stress during ECAP causes the atoms to migrate along the shearing direction and a decrease in the distance between nearest-neighbor atoms which promoting an increase in the local free volume associated with atomic dilatation. This means a structural transformation from short range order (SRO) to medium range order (MRO) [23]. Atomic local rearrangement as a result of deformation is a common feature in glassy alloys [24].

Another feature of diffraction patterns is a decrease in the intensity of $\mathrm{Al}$ peaks and their weak broadening with respect to the XRD pattern of the Al powder. Fig. $5 \mathrm{~b}$ shows a close examination of the (220) and (311) peaks from the XRD patterns depicted in Fig. 5a. Precise observation of Fig. 5b reveals weak broadening of the peaks for consolidated specimens compare to pure Al powder. The broadening and intensity reduction of the Al peaks may due to lattice strain and increasing the defects density of the $\mathrm{Al}$ phase as a result imposed intensive strains during severe plastic deformation [7].

\section{Fig. 5.}

Typical SEM micrographs of the composites containing different volume fractions of glassy particles are shown in Fig. 6. For all composites, no fracture of the AMG reinforcements was observed after ECAP, implying good workability of them during severe plastic deformation. As seen in Fig. 6a, the distribution of AMG particles in aluminum matrix for Al/5 vol.\% AMG 
composite is uniform and almost no clusters of glassy particles exist in the composite. According to Figs. $6 \mathrm{~b}$ and c, distribution of particles becomes less homogeneous by increasing the volume fraction of AMG reinforcements. Fig. 6c shows that the Al/15 vol.\% AMG composite consisted of clusters of AMG particles and particle-free zones.

Fig. 6.

One of the parameters used to quantify the particles distribution is the interparticle distance $\left(\lambda_{\text {inter }}\right)$ that defined as the average of the distances of each particle to its nearest neighbor. The coefficient of variation, $\mathrm{COV}$, is the statistical parameter that utilized for the comparison of the variations of different sets of measurements and to normalize them [25]. The COV is explained as the ratio of the standard deviation of a given measurements to their mean, $\mathrm{COV}(\mathrm{m})=\sigma \mathrm{m} / \mathrm{m}$, where $\sigma m$ is the standard deviation and $\mathrm{m}$ is the mean. COV values for a specific measurement will generally increase with increasing degree of inhomogeneity. The COV value of a certain parameter is dimensionless and shows values between 0 and 1. Fig. 7 shows the variations in $\operatorname{COV}\left(\lambda_{\text {inter }}\right)$ with different amount of AMG particles in the produced composites. It can be seen that by increasing the volume fraction of $A M G$ particles in the matrix, $\operatorname{COV}\left(\lambda_{\text {inter }}\right)$ is increased. Reducing the distribution homogeneity by increasing the amount of AMG particles attributed to their tendency for clumping together and so forming big agglomerates and clusters at high levels of reinforcements. Separation of these clusters to smaller ones and/or individual particles needs extra deformation of the soft particles to fill the gaps between the contact points of hard particles [26].

Fig. 7. 
Fig. 8 shows the FE-SEM micrographs of the grain structure of the composites. The elemental line analysis at the interface of $\mathrm{Al} / 10$ vol.\% $\mathrm{AMG}$ composite is also shown in Fig $8 \mathrm{~b}$. In all specimens, the microstructure of matrix consists of relatively fine and elongated grains along the shear deformation direction which is common feature in ductile powders consolidated by ECAP $[15,16]$. The average matrix grain sizes and their aspect ratios calculated from Fig. 8 are given in Table 1. The matrix microstructure in all composites consists of finer grains when compared to pure $\mathrm{Al}$, such that the grain size in the composites is found to be $\sim 1-1.5$ times smaller than that of pure Al. This refined microstructure of composites is attributed to the presence of reinforcement particles, which act as heterogeneous sites for grain nucleation [27]. In addition to the uniformity of particles in matrix, bonding quality between reinforcement and matrix and also porosity are other factors that affect the MMC properties. According to Figs. $8 \mathrm{~b}$ and c, for Al/5 vol.\% AMG and Al/10 vol.\% AMG composites, the Al matrix bonds well with the AMG particle. In contrast to ceramic reinforcements, the metallic glasses are more compatible with the metal matrix and make desirable interface bonding. On the other hand, flowing of the matrix around the particles at high pressure and temperature during ECAP, can improve the bond strength. For the Al/15 vol.\% AMG composite (Fig. 8d), some porosity and discontinuity can be observed in the interface of the reinforcement and matrix. In this case, since the plastic flow of matrix into the clusters is insufficient, the interfacial porosities are created. In the other words, clusters of reinforcing particles restrict the flow of matrix through particles. It is obvious that the particles in close contact with the matrix in all directions have stronger bonding with matrix compared to those particles having no bonding in some directions. From Fig. 8b, it can be observed that concentration of elements ( $\mathrm{Al}, \mathrm{Cu}$ and $\mathrm{Ti}$ ) sharply changed at the interface, implying the mutual diffusion of the elements between AMG particles and matrix doesn't occur 
for $\mathrm{Al} / 5$ vol.\% AMG composite (similar results is recorded for $\mathrm{Al} / 10$ vol.\% AMG composite). This indicates no reaction products are formed at the interface of matrix and reinforcements. Interfacial reactions do not happen when reinforcement particles are in the amorphous state and they react with metallic matrix only after crystallization [28]. Generally, interfacial reactions can impose negative effects in the expected properties of composite in two ways: first, degradation of AMG articles which would change the properties of them and, second, formation of brittle intermetallic phases along the interface of matrix and reinforcements that is detrimental to the strength of interface. From these results it can be concluded that neither pore nor chemical product is found along the interface of $\mathrm{Al} / 5 \mathrm{vol} . \% \mathrm{AMG}$ and $\mathrm{Al} / 10$ vol.\% AMG composites. This means successful densification of the composites without any undesirable effects of phase change.

Fig. 8.

Table 1.

\subsubsection{Density measurement}

Table 2 shows the results of density measurements. The relative densities of conventional ceramic particle reinforced composites are also given in the table. It can be seen that the relative densities of the currently developed Al/AMG composites are higher than those of the conventional ceramic reinforced composites produced by ECAP [29]. These contrasts happen due to two reasons. First, higher consolidation temperature $\left(250{ }^{\circ} \mathrm{C}\right)$ which causes the atomic diffusion to take place rapidly, and second, metallic particles which are highly deformable to flow smoothly during ECAP process. According to Lapovok et.al [30], as the sample passes 
through the vertical channel of the die, it reaches the shear plane in the ECAP and the pore shape changes from near spherical to elliptical shape aligned with the shear plane which is favorable for their closure. Relatively high temperature applied during consolidation cause to creating diffusive bonding between particles after the change in the pore shape which result in reduction of porosities. It has been proved that the self-diffusion coefficient of $\mathrm{Al}$ is enhanced due to the ECAP process which can be considered in this study too. Consequently, diffusion takes place fast enough to eliminate pores and increase the density. Also, presence of metallic particles as reinforcements which have more compatibility with matrix reduce the probability of pore formation in the areas near the interfaces. The other advantage of metallic glass as a reinforcement is its softness with respect to conventional ceramic reinforcements which increase the effect of severe deformation during consolidation.

The relative density of compacts decrease with increasing the amount of reinforcement particles specially for Al/15 vol.\% AMG composite (table 2). Several mechanisms include localized fragmentation; mechanical interlocking and rearrangement of the particles as a result of induced severe plastic deformation during ECAP are responsible for improved density of composites [31]. Presence of hard AMG particles prevent local accommodation of neighbor particles of matrix and also decrease the interfacial area of contact between matrix particles, thus, interfere the above mentioned mechanisms. Therefore, increasing the amount of AMG particles would impose negative effect on consolidation process.

\section{Table 2.}

\subsubsection{Mechanical properties}


The uniaxial compression behavior of the composites is presented in Fig. 9. Table 3 summarizes the mechanical properties of the composite. For comparison, the properties for the consolidated pure aluminum are also given. As seen in Fig. 9, the stress-strain curves of the samples show a saturation trend (the diagrams do not show considerable work hardening after yielding). This is the common behavior of the samples processed by SPD techniques that would not show considerable work hardening when they are tested by tensile or compression tests [32]. Also, a work softening-like behavior can be seen for Al/15 vol.\% AMG composite after yielding. The similar behavior has been reported for glass particles reinforced Al-based composites [6, 33]. As indicated in these researches, the clusters of reinforcing particles cause work softening to occur in composites with high levels of glassy reinforcements. Particle clustering produces high local stress concentration and thus provides crack nucleation sites and low energy propagation routes through connecting brittle particles. Nucleation and propagation of these cracks leads to work softening behavior of Al/15 vol.\% AMG composite. Fig. 9 shows that composites have a higher strength than the pure aluminum. Increasing trend in strength of the composites can be seen with increasing the amount of AMG particles to 10 vol.\%. In particular, Al/10 vol.\% exhibits a yield strength of about $184 \mathrm{MPa}$ with an appreciable plastic strain at fracture of about 0.48 . This indicates the positive role of hard reinforcement particles in improving the strength of composites.

Fig. 9.

Table 3.

Glass reinforcing particles are much harder than the matrix alloy. During ECAP, severe plastic strains imposed only in the matrix and the glassy particles deform elastically which approved by 
XRD results (fig. 5) in which no deformation induced crystallization observed in the composites. The significant increase in the mechanical strength of the composite compared to the pure aluminum arise from strengthening mechanisms due to the presence of micro sized reinforcement particles, including grain refinement strengthening [34], load transfer effect [34] and enhanced dislocation density induced by the difference in the coefficient of thermal expansion between the matrix and reinforcing particles [35, 36]. Grain refinement of the composite matrix increases the strength according to the well-known Hall-Petch equation:

$\sigma_{\mathrm{y}}=\sigma_{0}+k d^{-1 / 2}$

Where $\sigma_{\mathrm{y}}$ is the yield strength, $\sigma_{0}$ is the frictional stress, $k$ is the Hall-Petch slope and $d$ is the average grain size.

Based on the load transfer mechanism, the load is transferred from the matrix to the hard reinforcement during the compression test which enable composite to tolerate the higher compressive loads and so the strength will increase. Also, upon cooling from the consolidated temperature, dislocations can be generated in the vicinity of matrix/particles interface as a result of heavily built multidirectional thermal stress induced by the difference of the CTE between the matrix and the reinforcement. Thus, the strength improves due to the interaction between the produced dislocations.

Increasing the volume fraction of glass reinforcements would intensify three mentioned effects, hence, $\mathrm{Al} / 10$ vol.\% AMG composite exhibited higher strength than Al/5 vol.\% AMG. On the other hand, with further increase in reinforcement volume fraction to $15 \%$, a decrease in strength and ductility has been observed. This behavior can be attributed to three factors: 
1. The distribution of the reinforcements, which in the current case is due to clustering of the particles. Clustering and agglomeration of particles lead to decreasing the distance between interfaces and hence, the cracks which are initiated in the interfaces will propagate and connect with other cracks, and the ductility of composite decreases.

2. The porosity has a major effect on the strength and ductility of the composites. Porosities in composites can provide preferential sites for crack initiation and propagation.

3. A sound bonding of the AMG particles and the matrix is another factor that affects the final strength and ductility of samples. By increasing the volume fraction of reinforcements to $15 \%$, the bonding between the AMG particles and the matrix becomes weaker which has a negative effect on the strength and ductility.

According to Fig. 9, all composites exhibit improved ductility compared to ceramic reinforced composites with the same amount of reinforcements consolidated through ECAP process [20, 29]. This is attributed to the better compatibility of glass particles and matrix with respect to ceramic reinforcements and also higher fracture toughness and ductility of glass particles.

The Rule of Mixtures (ROM) is the simple modeling method commonly used to predict the mechanical properties of composites from the mechanical properties of matrix and reinforcements [37]. According to this model, the strength of the composites depends on the strength of constituents and is given as follows:

$\sigma_{c}=\sigma_{m}(1-f)+\sigma_{r} f$

Where $\sigma_{c}, \sigma_{m}$ and $\sigma_{r}$ are the yield strength of composite, matrix and reinforcement, respectively and $f$ is the volume fraction of reinforcement particles. According to Table 2, by neglecting the 
porosity content of pure aluminum, the yield strength of the matrix is $121 \mathrm{MPa}$. The approximate yield strength of $\mathrm{Al}_{65} \mathrm{Cu}_{20} \mathrm{Ti}_{15}$ particles can be obtained through hardness data of bulk specimens consolidated from these particles. As reported in previous studies [38, 39], the hardness of specimens with fully glass structure and negligible porosity is about $550 \mathrm{Hv}$. Several publications reported that the hardness is approximately three times of yield strength in the brittle materials such as BMGs and ceramics [40-43]. Hence, the yield strength of reinforcement particles is considered to be $1350 \mathrm{MPa}$. Fig. 10 shows the variation of yield strength with the volume fraction of AMG particles calculated by the ROM model. It is obvious that with increasing the amount of reinforcement particles, experimental yield strength deviates more from the curve. The experimental values obtained for A1/5 vol.\% AMG composite is in a good agreement with the ROM calculations. However, by increasing the volume of reinforcement to $10 \%$, theoretical strength becomes greater than experimental one and a considerable deviation can be seen for Al/15 vol.\% AMG composite. The ROM assumes that the properties of a composite are volume-weighted averages of the properties of the components without considering any defects or discontinuities in the matrix or reinforcements. The AMG particles distribution inhomogeneity and also presence of porosity in the matrix and interface of matrix /reinforcements are responsible for divergence of experimental data from ROM-based calculations for composites having higher volume fractions of AMG particles.

Fig. 10.

\section{Conclusions}

In this study, the ECAP process was used as a consolidation technique to produce bulk aluminum base composites with varying percentages of $\mathrm{Al}_{65} \mathrm{Cu}_{20} \mathrm{Ti}_{15}$ (AMG) reinforcement particles. The 
microstructure and mechanical properties of the composites produced were investigated and the conclusions are summarized as follows:

1. ECAP has proved to be effective tool in producing bulk Al-matrix composites with AMG reinforcements without altering the amorphous nature of the reinforcements.

2. The severe shear deformation during ECAP shifted amorphous peak to higher angles in XRD patterns in $\mathrm{Al} / 10$ vol.\% $\mathrm{AMG}$ and $\mathrm{Al} / 15 \mathrm{vol} . \% \mathrm{AMG}$ composites. This can be attributed to the structural dilatation and local atomic rearrangement in the $\mathrm{Al}_{65} \mathrm{Cu}_{20} \mathrm{Ti}_{15}$ reinforcements.

3. Uniform distribution of reinforcements with no interfacial reaction products could be ensured in AMG reinforced composite produced through ECAP process.

4. The compressive yield strength of the composites improved when the volume fraction of $\mathrm{Al}_{65} \mathrm{Cu}_{20} \mathrm{Ti}_{15}$ reinforcements increased. When compared to the strength of pure $\mathrm{Al}$, the $\mathrm{Al} / 10$ vol.\% AMG composite showed 52\% increase in strength.

5. By increasing the AMG quantities in the aluminum matrix, the ductility decreased. Micro size porosities along with weak matrix/reinforcement interface bonding were responsible for this behavior. These also lead to substantial deviation of compressive yield strength of Al/15 vol.\% AMG composite from that calculated using ROM model.

\section{Acknowledgment}

The authors are thankful to Center of Excellence for High Strength Alloys Technology (CEHSAT) of IUST University. They also thank the support of Iran National Science Foundation (INSF). 


\section{References}

[1] F. Dobes, M. Besterci, B. Ballokova, K. Sulleiova, P. Dymacek, Analysis of creep fracture in $\mathrm{Al}-\mathrm{Al}_{4} \mathrm{C}_{3}$ composite after ECAP, Mater. Sci. Eng. A 532 (2012) 567- 572.

[2] R. Jamaati, M.R. Toroghinejad, A. Najafizadeh, An alternative method of processing MMCs by CAR process, Mater. Sci. Eng. A 527 (2010) 2720-2724.

[3] L. Ceschini, G. Minak, A. Morri, Forging of the AA2618/20 vol.\% $\mathrm{Al}_{2} \mathrm{O}_{3}$ p composite: effects on microstructure and tensile properties, Comp. Sci. Technol. 69 (2009) 1783-1789.

[4] R. Zheng, X. Hao, Y. Yuan, Z. Wang, Effect of high volume fraction of $\mathrm{B}_{4} \mathrm{C}$ particles on the microstructure and mechanical properties of aluminum alloy based composites, J. Alloys Compd. 576 (2013) 291-298.

[5] D.L. Zhang, C.C. Koch, R.O. Scattergood, The role of new particle surfaces in synthesizing bulk nanostructured metallic materials by powder metallurgy, Mater. Sci. Eng. A 516 (2009) $270-275$.

[6] S. Scudino, G. Liu, K.G. Prashanth, B. Bartusch, K.B. Surreddi, B.S. Murty, J. Eckert, Mechanical properties of Al-based metal matrix composites reinforced with Zr-based glassy particles produced by powder metallurgy, Acta Mater. 57 (2009) 2029-2039.

[7] R. Zheng, H. Yan, T. Liu, K. Ameyama, C. Ma, Microstructure and mechanical properties of aluminum alloy matrix composites reinforced with Fe-based metallic glass particles, Mater. Des. 53 (2014) 512-518. 
[8] D.V. Dudina, K. Georgarakis, Y. Li, M. Aljerf, A. LeMoulec, A.R. Yavari, A. Inoue, A magnesium alloy matrix composite reinforced with metallic glass, Comp. Sci. Technol. 69 (2009) 2734-2736.

[9] A. Inoue, N. Nishiyama, New bulk metallic glasses for applications as sensing, chemical, and structural materials, MRS Bull. 32 (8) (2007) 651-658.

[10] Z. Wang, K.G. Prashanth, S. Scudino, A.K. Chaubey, D.J. Sordelet, W.W. Zhang, Y.Y. Li, Tensile properties of $\mathrm{Al}$ matrix composites reinforced with in situ devitrified $\mathrm{Al}_{84} \mathrm{Gd}_{6} \mathrm{Ni}_{7} \mathrm{Co}_{3}$ glassy particles, J. Alloys Compd. 586 (2014) 419-422.

[11] M. Krasnowski, A. Antolak-Dudka, T. Kulik, Bulk amorphous $\mathrm{Al}_{85} \mathrm{Fe}_{15}$ alloy and $\mathrm{Al}_{85} \mathrm{Fe}_{15^{-}}$ B composites with amorphous or nanocrystalline-matrix produced by consolidation of mechanically alloyed powders, Intermetallics 19 (2011) 1243-1249.

[12] M. Alizadeh, M.H. Paydar, Fabrication of $\mathrm{Al} / \mathrm{SiC}_{\mathrm{P}}$ composite strips by repeated rollbonding (RRB) process, J. Alloys Compd. 477 (2009) 811-816.

[13] J. Williams, Thermo-mechanical processing of high-performance Ti alloys: recent progress and future needs, J. Mater. Process. Technol. 117 (2001) 370-373.

[14] J.M. Torralba, C.E. da Costa, F. Velasco, P/M aluminum matrix composites: an overview, J. Mater. Process. Technol. 133 (2003) 203-206.

[15] A.K. Mukhopadhyay, H.M. Flower, and T. Sheppard, Development of Mechanical Properties in AA 8090 Alloy Produced by Extrusion Processing, Mater. Sci. Technol. 6 (1990) 461-468. 
[16] S. Goussous, W. Xu, X. Wu, K. Xia, Al-C nanocomposites consolidated by back pressure equal channel angular pressing, Comp. Sci. Technol. 69 (2009) 1997-2001.

[17] R. Casati, F. Bonollo, D. Dellasega, A. Fabrizi, G. Timelli, A. Tuissi, M. Vedani, Ex situ Al-Al2O3 ultrafine grained nanocomposites produced via powder metallurgy, J. Alloys Compd. 615 (2013) 386-388.

[18] H. Pang Ng, C. Haase, R. Lapovok, Y. Estrin, Improving sinterability of Ti-6Al-4V from blended elemental powders through equal channel angular pressing, Mater. Sci. Eng. A 565 (2013) 396-404.

[19] M. Kubota, X. Wu, W. Xu, K. Xia, Mechanical properties of bulk aluminum consolidated from mechanically milled particles by back pressure equal channel angular pressing, Mater. Sci. Eng. A 527 (2010) 6533-6536.

[20] M. Balog, P.Yu, M.Qian, M.Behulova, P.Svec Sr, R.Cicka, Nanoscaled Al-AlN composites consolidated by equal channel angular pressing (ECAP) of partially in situ nitride $\mathrm{Al}$ powder, Mater. Sci. Eng. A 562 (2013) 190-195.

[21] J.B. Fogagnolo, F. Velasco, M.H. Robert, J.M. Torralba, Effect of mechanical alloying on the morphology, microstructure and properties of aluminium matrix composite powders, Mater. Sci. Eng. A 342 (2003) 131-143.

[22] K.U. Kainer, Metal matrix composites, John Wiley \& Sons, Weinheim, August 2006.

[23] X.Q. Guo, D.V.Louzguine, S.Yamaura, L.Q. Ma, W. Sun, M. Hasegawa, A. Inoue, Hydrogen absorption in Ti-Zr-Ni-Cu amorphous alloy, Mater. Sci. Eng. A 338 (2002) 97-100. 
[24] S.W. Lee, M.Y. Huh, E. Fleury, J.C. Lee, Crystallization-induced plasticity of $\mathrm{Cu}-\mathrm{Zr}$ containing bulk amorphous alloys, Acta Mater. 54 (2006) 349-355.

[25] N. Yang, J. Boselli, I. Sinclair, Simulation and quantitative assessment of homogeneous and inhomogeneous particle distributions in particulate metal matrix composites, J. Microsc. 201 (2001) 189-200.

[26] Z. Razavi Hesabi, H.R. Hafizpour, A. Simchi, An investigation on the compressibility of aluminum/nano-alumina composite powder prepared by blending and mechanical milling, Mater. Sci. Eng. A 454-455 2007 89-98.

[27] F.J. Humphreys, M. Hatherly, Recrystallization and Related Annealing Phenomena, second ed., Elsevier Science Ltd, United Kingdom, 2004.

[28] P. Yu, L.C. Zhang, W.Y. Zhang, J. Das, K.B. Kim, J. Eckert, Interfacial reaction during the fabrication of Ni60Nb40 metallic glass particles-reinforced Al based MMCs Mater. Sci. Eng. A 444 (2007) 206-213.

[29] R. Derakhshandeh. H.A. Jenabali Jahromi, An investigation on the capability of equal channel angular pressing for consolidation of aluminum and aluminum composite powder, Mater. Des. 32 (2011) 3377-3388.

[30] R. Lapovok, D. Tomus, C. Bettles, Shear deformation with imposed hydrostatic pressure for enhanced compaction of powder, Scripta Mater. 58 (2008) 898-901.

[31] R. Lapovok, D. Tomus, B.C. Muddle, Low-temperature compaction of Ti-6Al-4V powder using equal channel angular extrusion with back pressure, Mater. Sci. Eng. A 490 (2008) 171180. 
[32] R.Z. Valiev, T.G. Langdon, Principles of equal-channel angular pressing as a processing tool for grain refinement, Prog. Mater. Sci. 51 (2006) 881-981.

[33] Z. Wang, J. Tan, S. Scudino, B.A. Sun, R.T. Qu, J. Heb, K.G. Prashanth, W.W. Zhang, Y.Y. Li, J. Eckert, Mechanical behavior of Al-based matrix composites reinforced with $\mathrm{Mg}_{58} \mathrm{Cu}_{28.5} \mathrm{Gd}_{11} \mathrm{Ag}_{2.5}$ metallic glasses, Adv. Powder Tech. 25 (2014) 635-639.

[34] L.C. Davis, C. Andres, J.E. Allison, Microstructure and strengthening of metal matrix composites, Mater. Sci. Eng. A 294 (1998) 40-45.

[35] S. Amirkhanlou, M. Ketabchi, N. Parvin, A. Orozco-Caballero, F. Carreno, Homogeneous and ultrafine-grained metal matrix nanocomposite achieved by accumulative press bonding as a novel severe plastic deformation process, Scripta Mater. 100 (2015) 40-43.

[36] S. Pal, V.V. Bhanuprasad, R. Mitra, K.K. Ray, The effect of thermal cycling on creep behavior of powder metallurgy processed and hot rolled $\mathrm{Al}$ and $\mathrm{Al}-\mathrm{SiC}$ particulate composites, Metall. Mater. Trans. A 40A (2009) 3171-3185.

[37] J. Chen, P. Niu, T. Wei, L. Hao, Y. Liu, X. Wang, Y. Peng, Fabrication and mechanical properties of $\mathrm{AlCoNiCrFe}$ high-entropy alloy particle reinforced $\mathrm{Cu}$ matrix composites, J. Alloys Compd. 649 (2015) 630-634.

[38] D. Roy, A. Sinha, P.P. Chattopadhyay, I. Manna, Nanoindentation behavior of bulk metastable Al65Cu20Ti15 alloy prepared by consolidation of the ball milled powder, Mater. Sci. Eng. A 528 (2011) 8047-8050. 
[39] D. Roy, R. Mitra, T. Chudoba, Z.Witczak, W. Lojkowski, H.J. Fecht, I. Manna, Structure and mechanical properties of $\mathrm{Al}_{65} \mathrm{Cu}_{20} \mathrm{Ti}_{15}$-based amorphous/nanocrystalline alloys prepared by high-pressure sintering, Mater. Sci. Eng. A 497 (2008) 93-100.

[40] L. Lu, R. Schwaiger, Z.W. Shan, M. Dao, K. Lu, S. Suresh, Nano-sized twins induce high rate sensitivity of flow stress in pure copper, Acta Mater. 53 (2005) 2169-2179.

[41] X.H. An, S.D. Wu, Z.F. Zhang, R.B. Figueiredo, N. Gao, T.G. Langdon, Evolution of microstructural homogeneity in copper processed by high-pressure torsion, Scr. Mater. 63 (2010) $560-563$.

[42] V. Keryvin, V.H. Hoang, J. Shen, Hardness, toughness, brittleness and cracking systems in an iron-based bulk metallic glass by indentation, Intermetallics 17 (2009) 211-217.

[43] R.L. Narayan, K. Boopathy, I. Sen, D.C. Hofmann, U. Ramamurty, On the hardness and elastic modulus of bulk metallic glass matrix composites, Scr. Mater. 63 (2010) 768-771.

\section{Figure captions:}

Fig. 1. Two dimensional schematic of copper tube filled with powders (Dimensions are in $\mathrm{mm}$ ).

Fig. 2. (a) SEM micrograph, and (b) particles size distribution of gas atomized pure aluminum powder.

Fig. 3. (a) SEM micrograph, EDS spectra, and (b) particles size distribution of ball milled $\mathrm{Al}_{65} \mathrm{Cu}_{20} \mathrm{Ti}_{15}$ particle.

Fig. 4. SEM micrographs of blended composite powders with (a) 5, (b) 10 , and (c) 15 vol\% of AMG reinforcement particles (Pure $\mathrm{Al}$ and $\mathrm{AMG}$ particles are in gray and white, respectively). 
Fig. 5. (a) XRD patterns and (b) Broadening of (220) and (311) peaks for the AMG reinforced composites and pure Al.

Fig. 6. SEM micrographs of the composites with (a) 5, (b) 10, and (c) 15 vol\% of AMG reinforcement particles.

Fig. 7. Variation of $\operatorname{COV}\left(\lambda_{\text {inter }}\right)$ with amount of reinforcement particles.

Fig. 8. Grain structure of (a) pure aluminum and the composites with (b) 5 vol\% (and EDS line analysis along line AB), (c) 10 vol\%, and (d) 15 vol\% of AMG reinforcement particles.

Fig. 9. True stress-true strain curves of consolidated pure $\mathrm{Al}$ and different Al/AMG composites.

Fig. 10. Experimental yield strength and calculated values obtained from the rule of mixtures (ROM).

\section{Table captions:}

Table 1. Grain characteristics of pure Al and Al/AMG composites with different amounts of reinforcing particles.

Table 2. Density, porosity percentage, and relative density of pure Al and different Al/AMG composites compared with those of conventional ceramic reinforced composites.

Table 3. The compressive mechanical properties of the AMG reinforced composites and Pure Al. 
Table 1. Grain characteristics of pure $\mathrm{Al}$ and $\mathrm{Al} / \mathrm{AMG}$ composites with different amounts of reinforcing particles.

\begin{tabular}{ccc}
\hline Sample & Grain size $(\mu \mathrm{m})$ & Aspect ratio \\
\hline Pure Al & $1.45 \pm 2.3$ & $1.88 \pm 0.58$ \\
$\mathrm{Al} / 5$ vol.\% AMG & $1.11 \pm 2$ & $2.18 \pm 0.61$ \\
$\mathrm{Al} / 10$ vol.\% AMG & $1.08 \pm 1.8$ & $2.01 \pm 0.68$ \\
$\mathrm{Al} / 15$ vol.\% AMG & $1.16 \pm 2.1$ & $1.91 \pm 0.52$ \\
\hline
\end{tabular}

Table 2. Density, porosity percentage, and relative density of pure Al and different Al/AMG composites compared with those of conventional ceramic reinforced composites.

\begin{tabular}{ccccc}
\hline Sample & $\begin{array}{c}\text { Theoretical } \\
\text { density }(\mathrm{g} / \mathrm{cm} 3)\end{array}$ & $\begin{array}{c}\text { Bulk density } \\
(\mathrm{g} / \mathrm{cm} 3)\end{array}$ & $\begin{array}{c}\text { Relative } \\
\text { density }(\%)\end{array}$ & $\begin{array}{c}\text { Porosity } \\
\text { percentage }(\%)\end{array}$ \\
\hline Pure $\mathrm{Al} *$ & 2.700 & 2.675 & 99.07 & 0.93 \\
$\mathrm{Al} / 5$ vol.\% AMG * & 2.755 & 2.723 & 98.83 & 1.17 \\
$\mathrm{Al} / 10$ vol.\% AMG * & 2.810 & 2.752 & 97.94 & 2.06 \\
$\mathrm{Al} / 15$ vol.\% $\mathrm{AMG}^{*}$ & 2.865 & 2.616 & 91.30 & 8.70 \\
$\mathrm{Al} / 5$ vol\% $\mathrm{Al}_{2} \mathrm{O}_{3}[27]$ & - & - & 95.79 & 4.21 \\
$\mathrm{~A} 1 / 10$ vol\% $\mathrm{Al}_{2} \mathrm{O}_{3}[27]$ & - & - & 92.21 & 7.79 \\
$\mathrm{Al} / 15$ vol\% $\mathrm{Al}_{2} \mathrm{O}_{3}[27]$ & - & - & 88.72 & 11.28 \\
\hline
\end{tabular}

* This reseach

Table 3. The compressive mechanical properties of the AMG reinforced composites and Pure Al.

\begin{tabular}{ccc}
\hline Sample & Yield Strength $(\mathrm{MPa})$ & Barreling strain $(\%)$ \\
\hline Pure Al & 121 & 0.59 \\
$\mathrm{Al} / 5$ vol.\% AMG & 168 & 0.5 \\
$\mathrm{Al} / 10$ vol.\% AMG & 184 & 0.48 \\
$\mathrm{Al} / 15$ vol.\% AMG & 153 & 0.42 \\
\hline
\end{tabular}




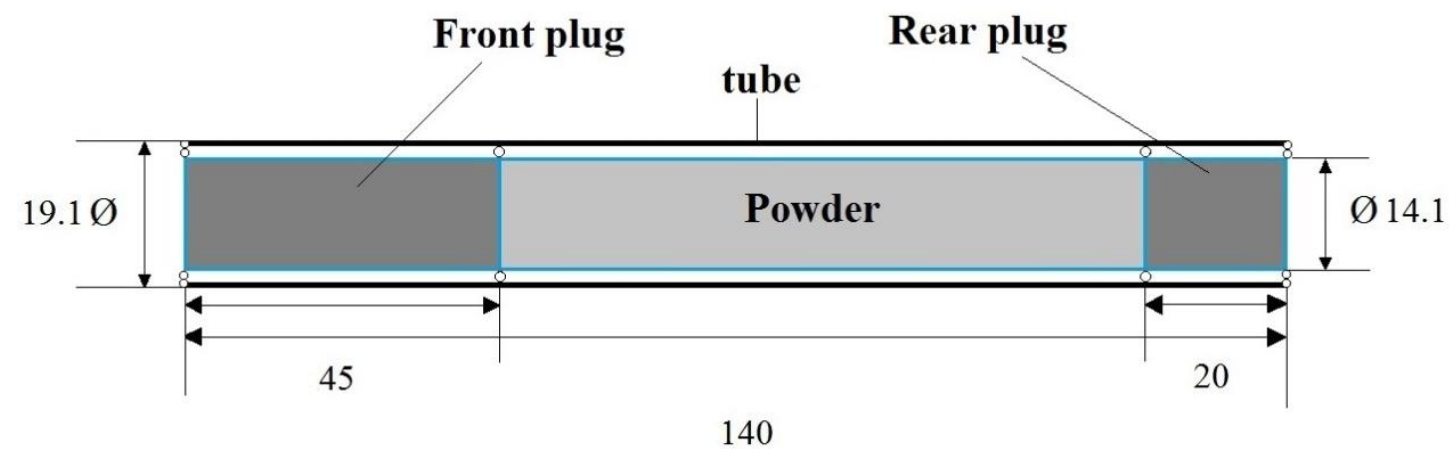

Fig. 1. Two dimensional schematic of copper tube filled with powders (Dimensions are in $\mathrm{mm}$ ).
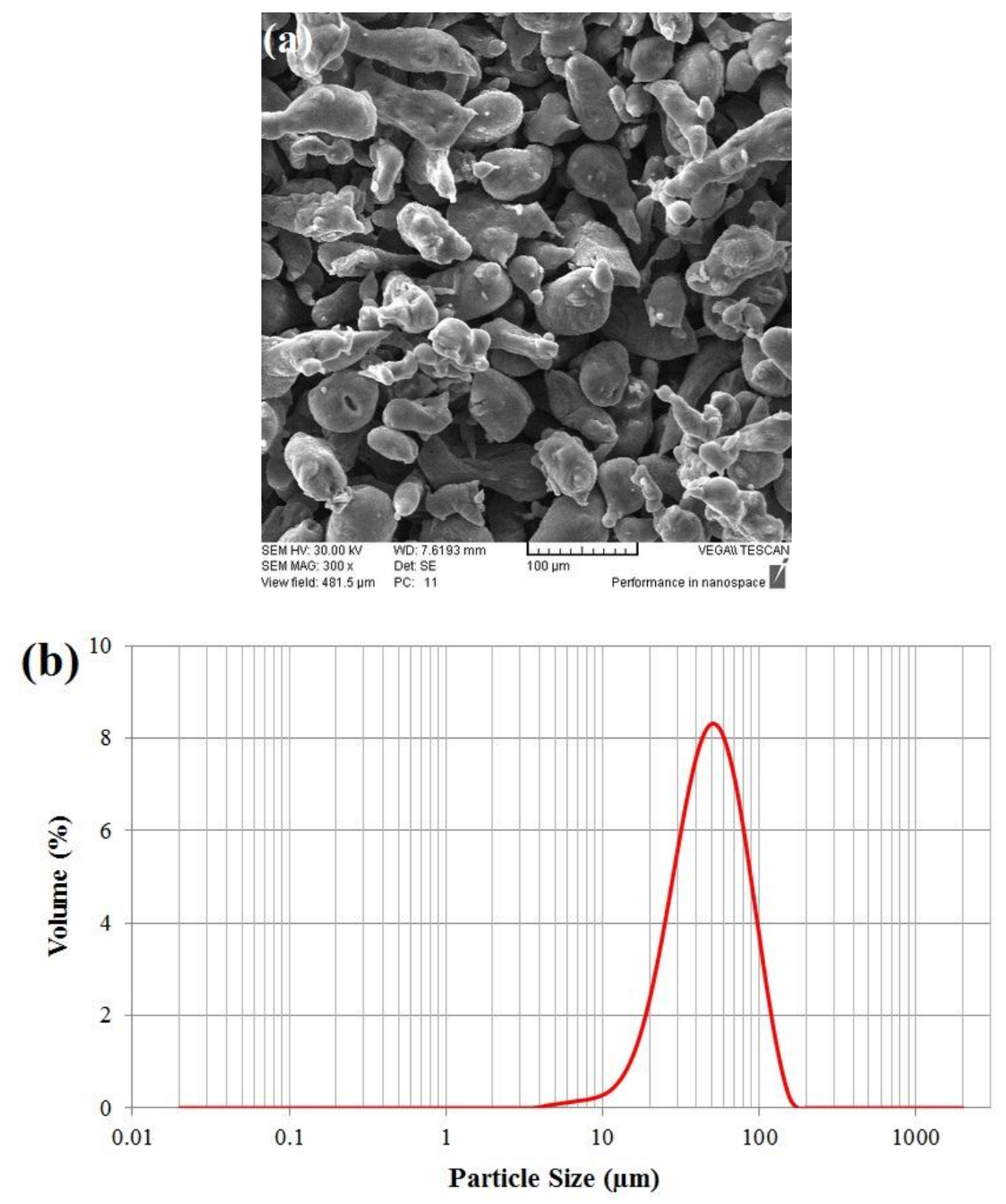

Fig. 2. (a) SEM micrograph, and (b) particles size distribution of gas atomized pure aluminum powder. 

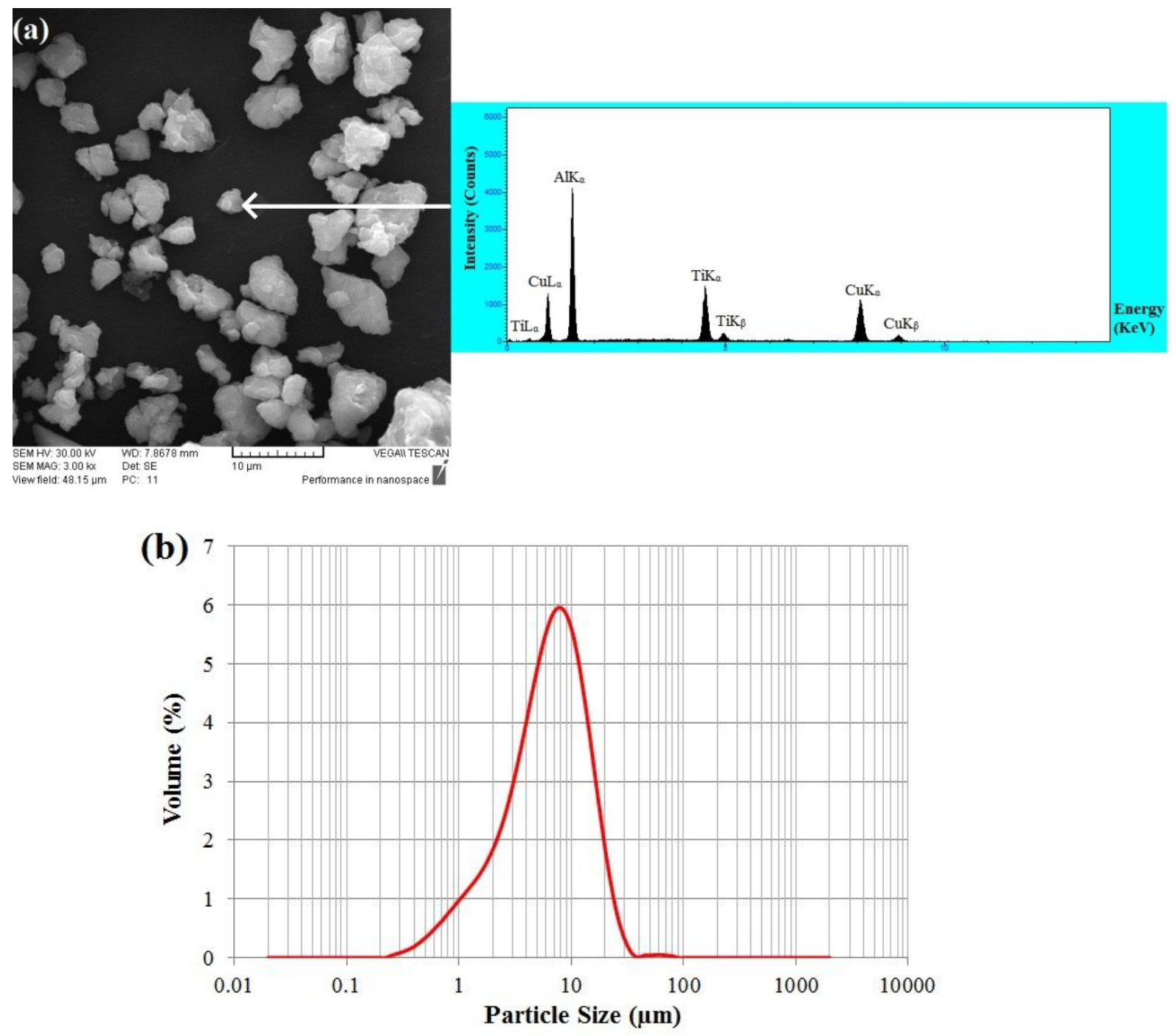

Fig. 3. (a) SEM micrograph, EDS spectra, and (b) particles size distribution of ball milled $\mathrm{Al}_{65} \mathrm{Cu}_{20} \mathrm{Ti}_{15}$ particle. 


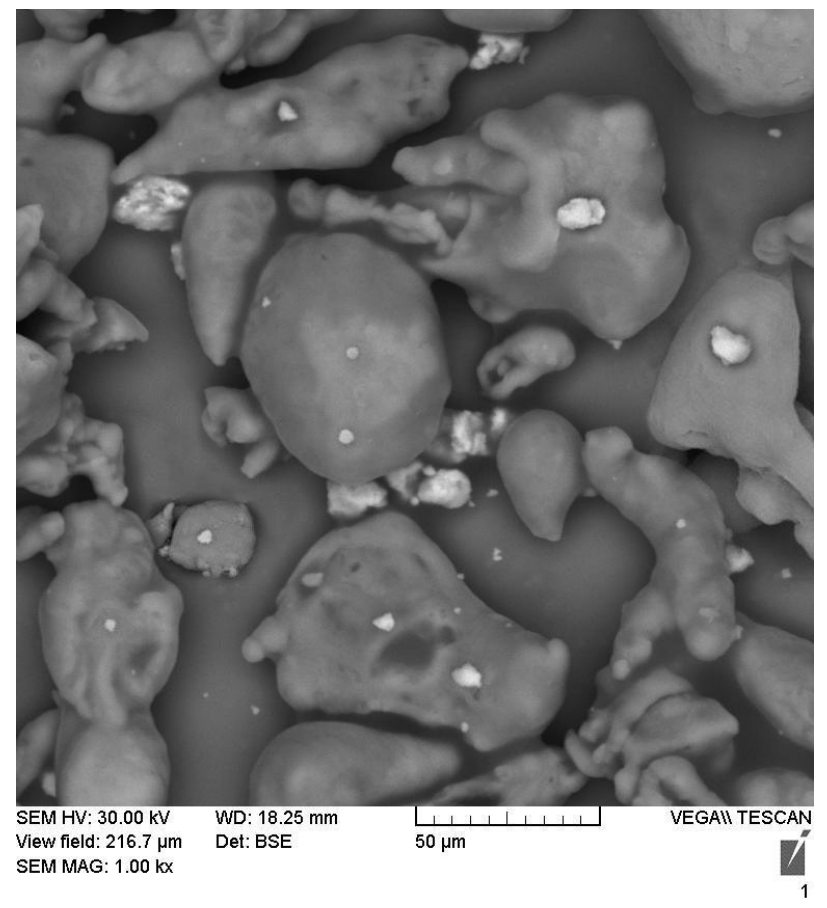

a)

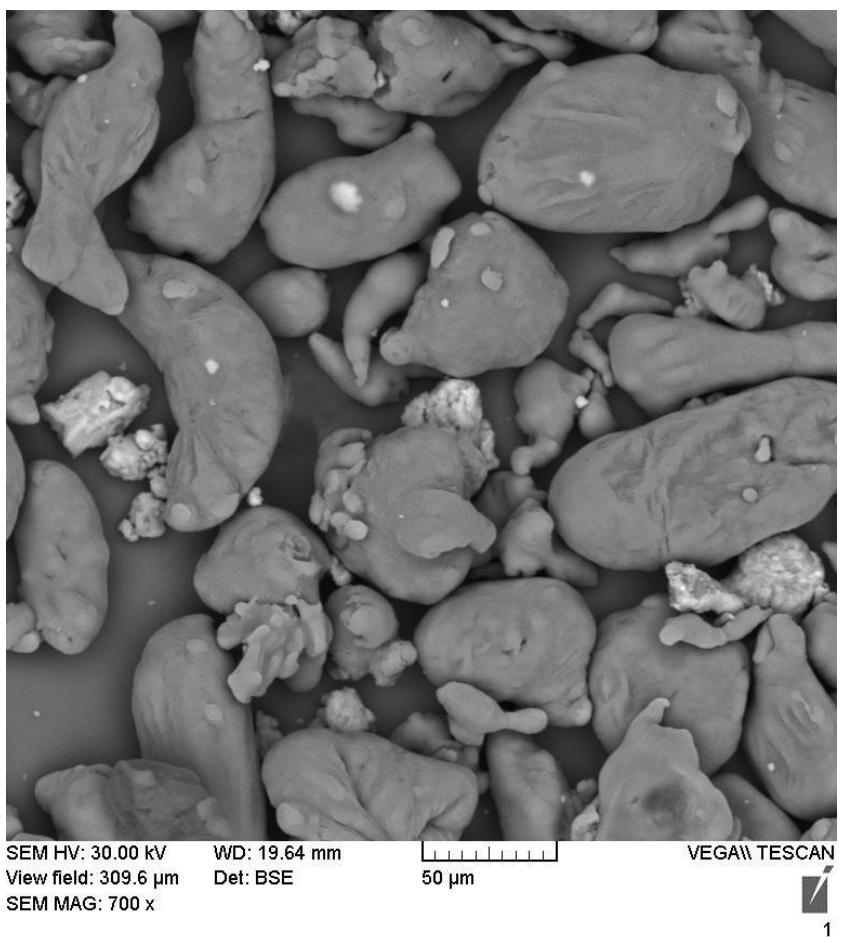

b) 


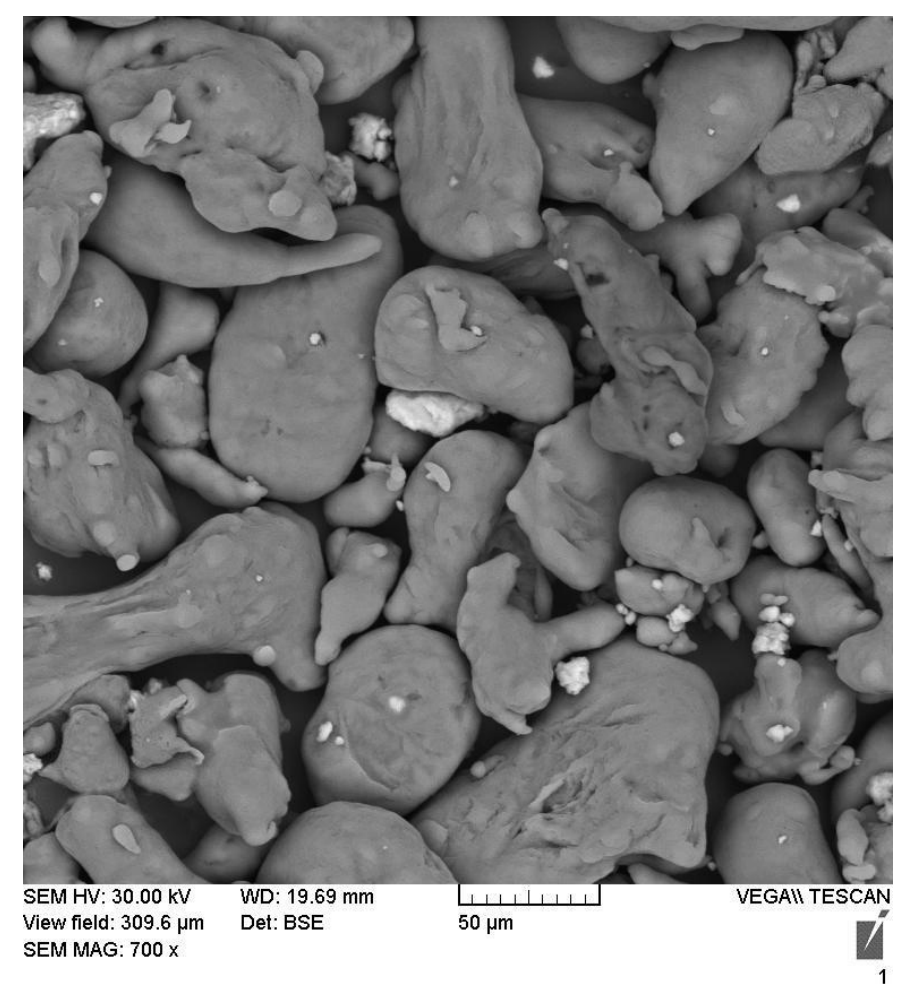

c)

Fig. 4. SEM micrographs of blended composite powders with (a) 5, (b) 10, and (c) 15 vol\% of AMG reinforcement particles (Pure $\mathrm{Al}$ and $\mathrm{AMG}$ particles are in gray and white, respectively). 


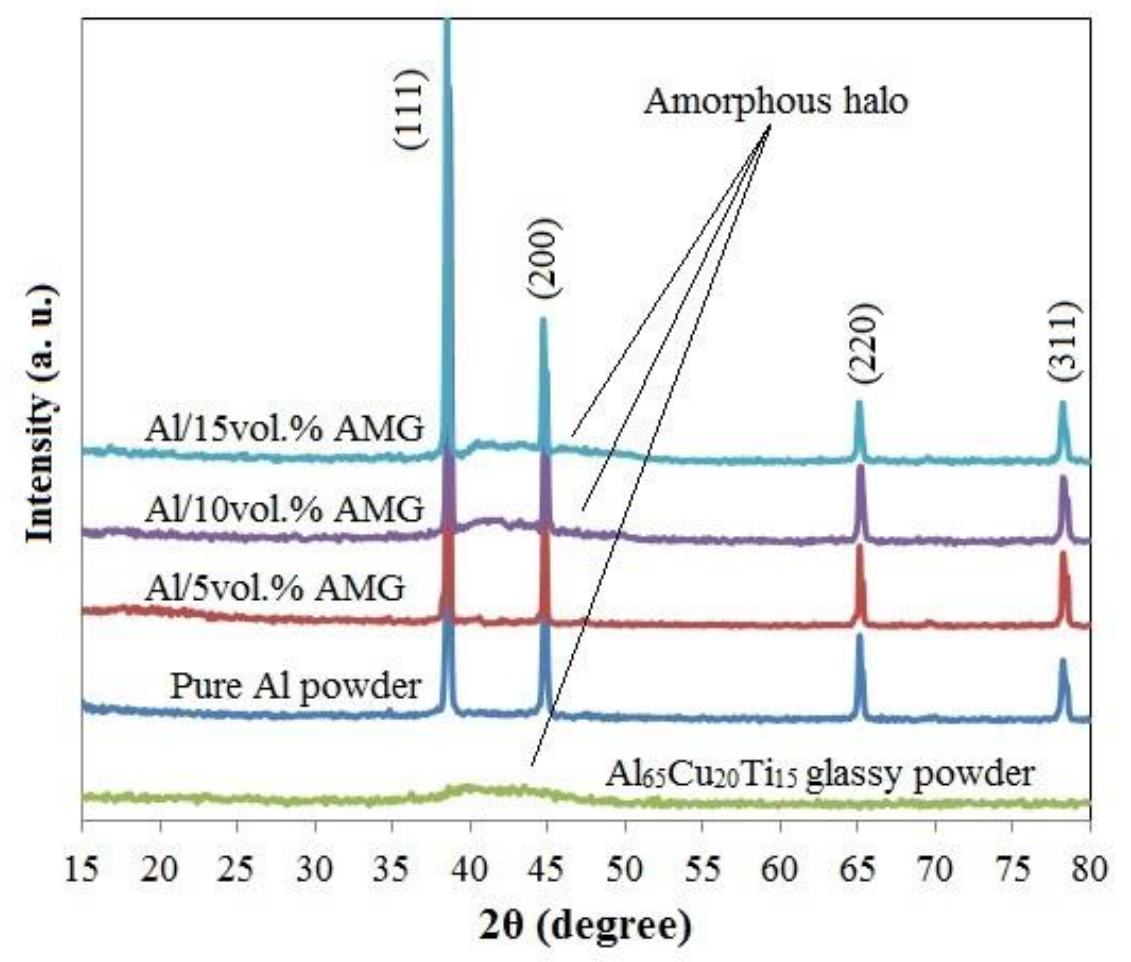

(a)

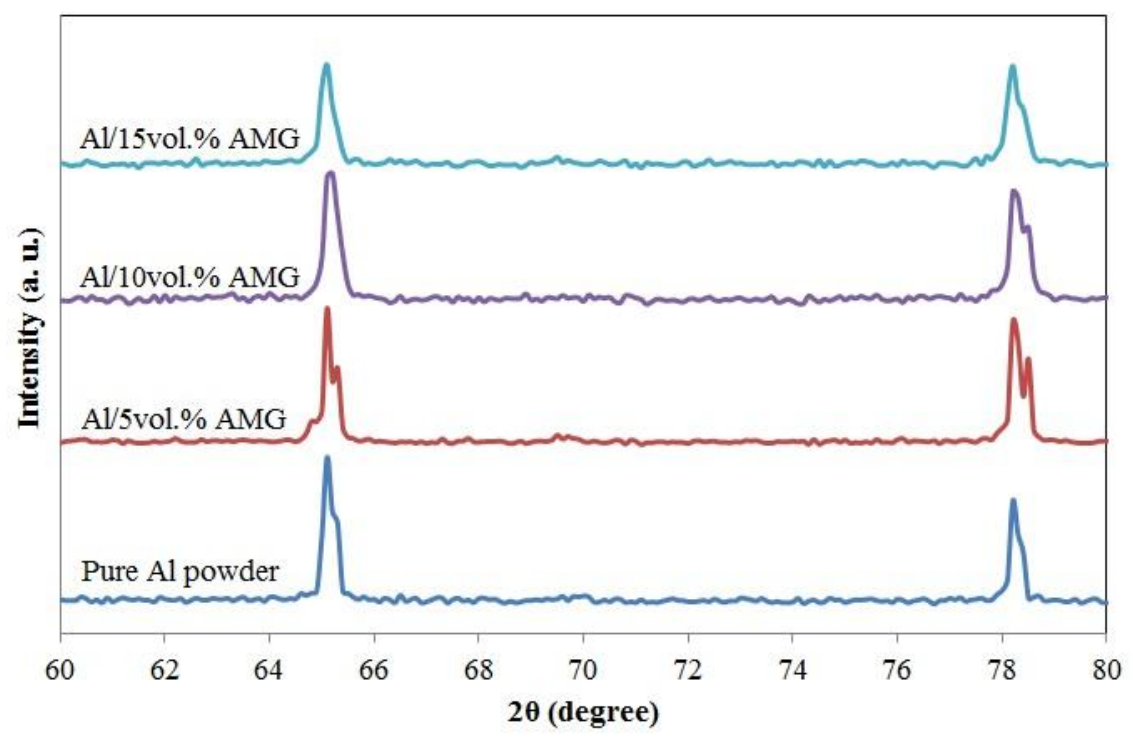

(b)

Fig. 5. (a) XRD patterns and (b) Broadening of (220) and (311) peaks for the AMG reinforced composites and pure Al. 

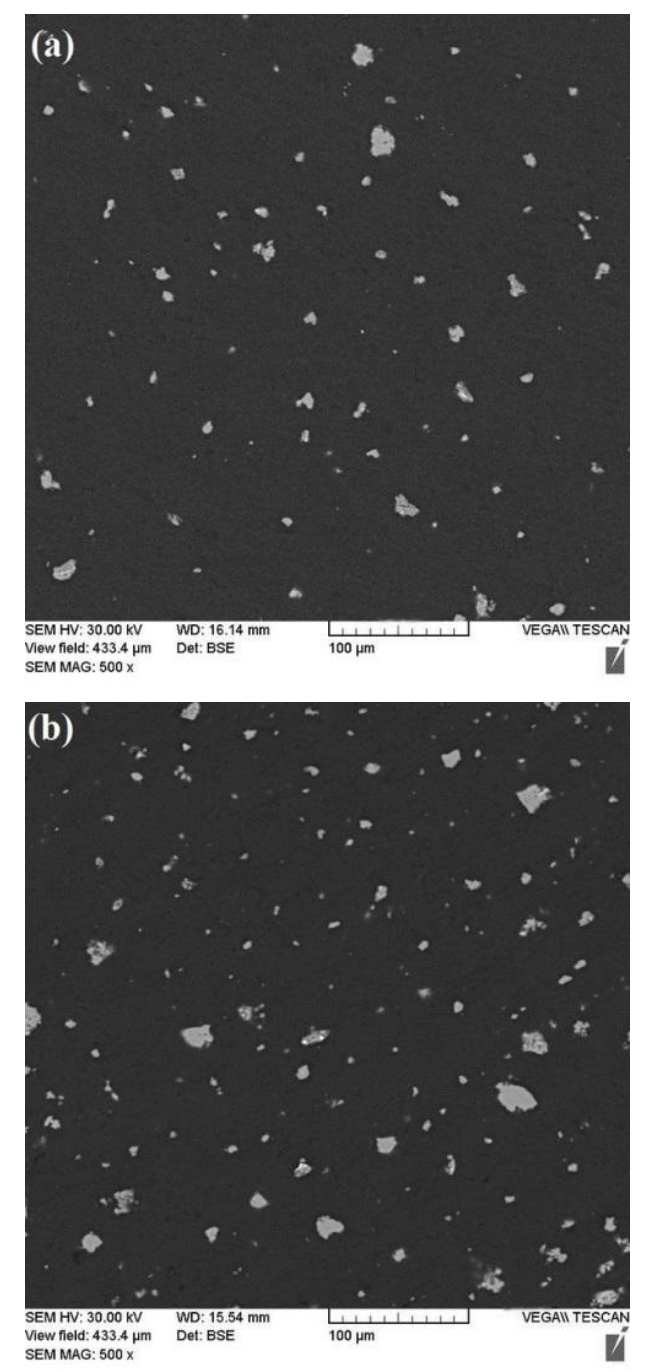


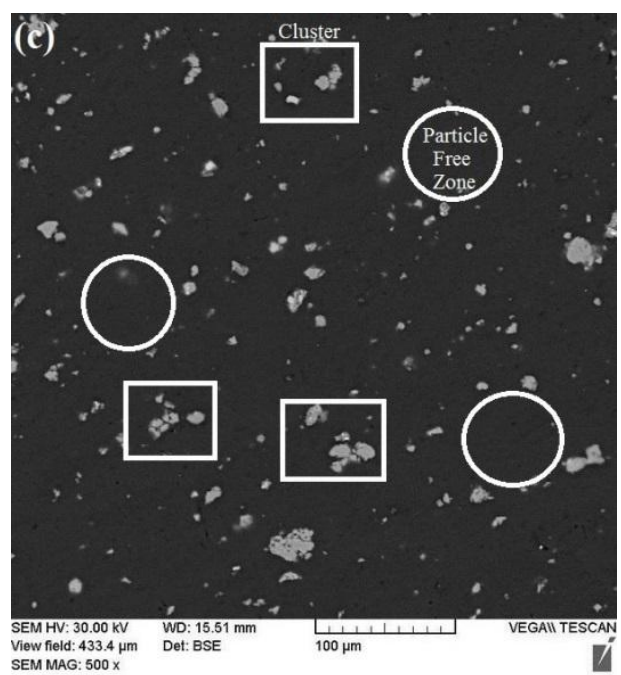

Fig. 6. SEM micrographs of the composites with (a) 5, (b) 10, and (c) $15 \mathrm{vol} \%$ of AMG reinforcement particles.

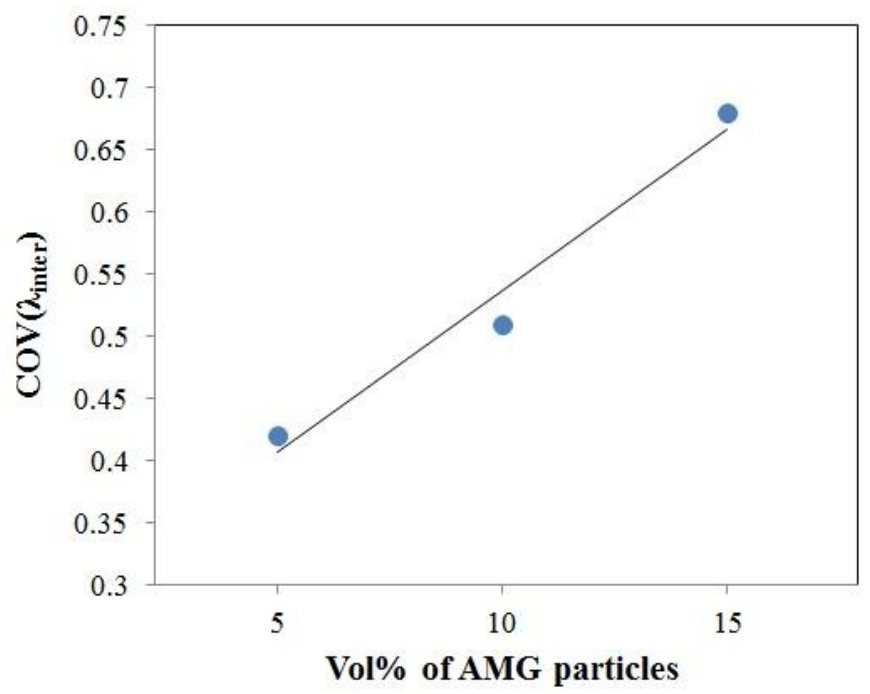

Fig. 7. Variation of $\operatorname{COV}\left(\lambda_{\text {inter }}\right)$ with amount of reinforcement particles. 

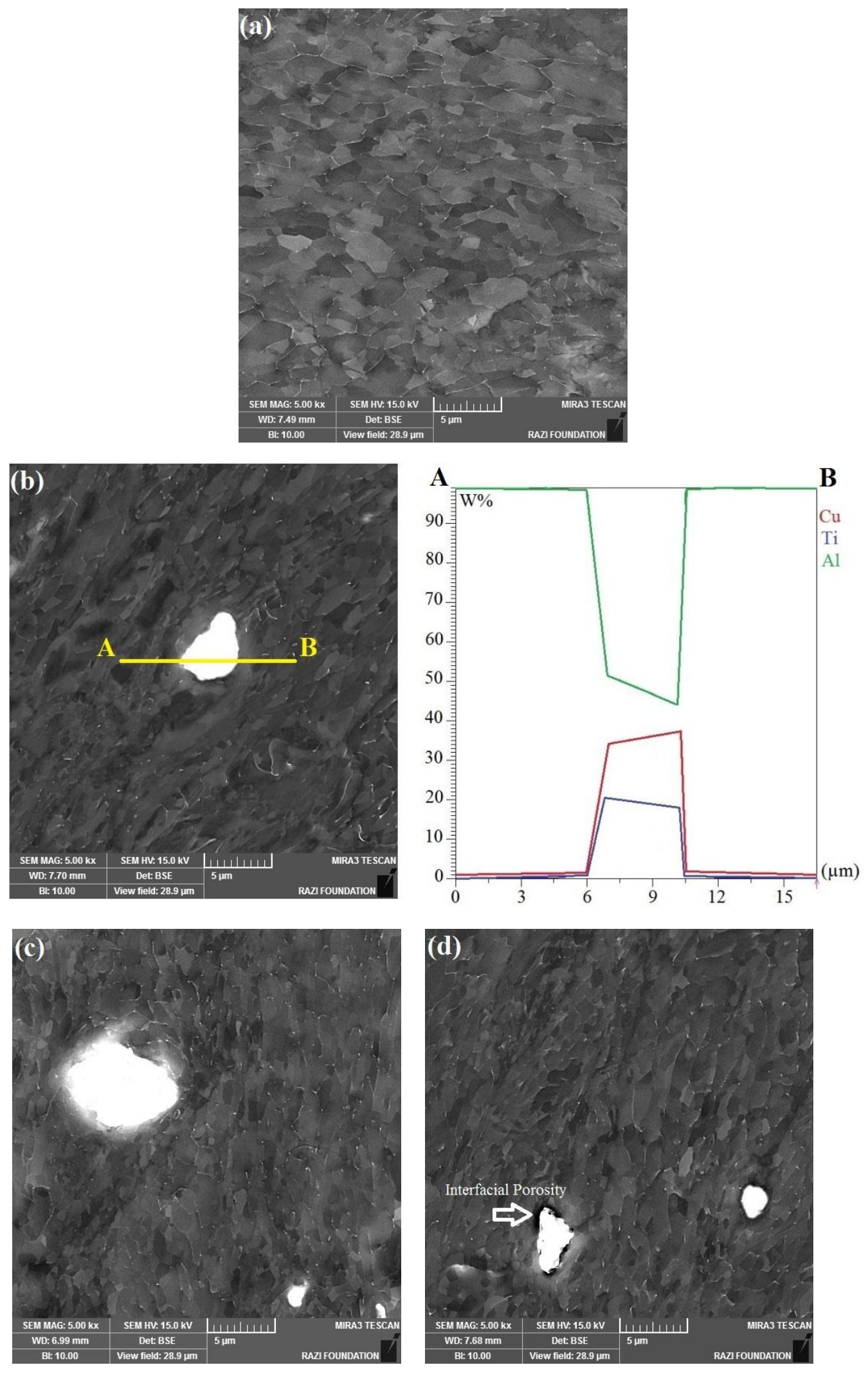
Fig. 8. Grain structure of (a) pure aluminum and the composites with (b) 5 vol\% (and EDS line analysis along line AB), (c) 10 vol\%, and (d) 15 vol\% of AMG reinforcement particles.

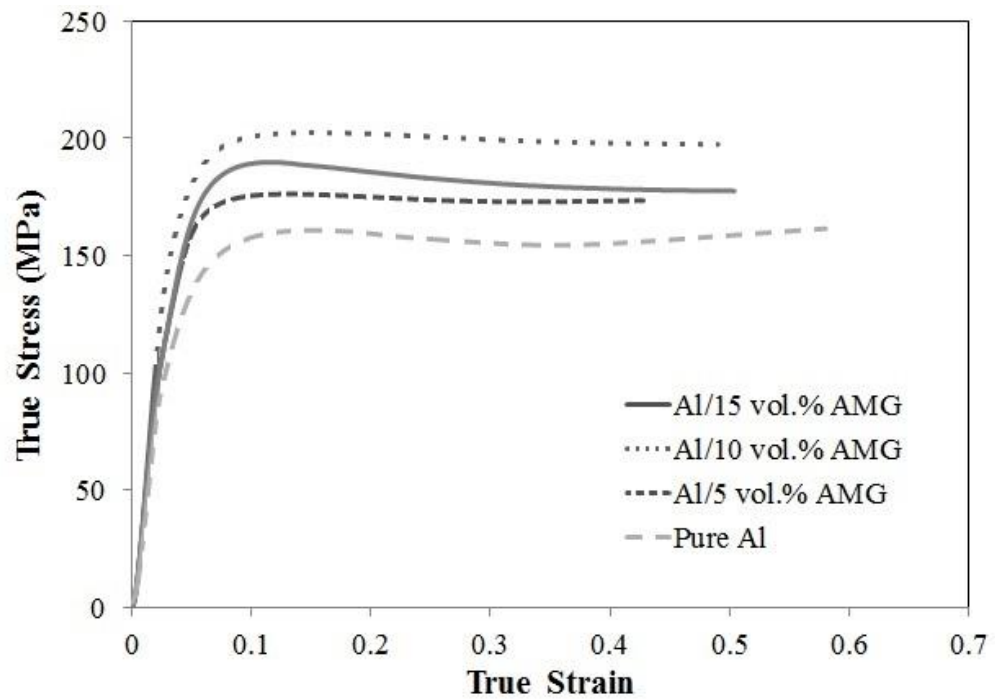

Fig. 9. True stress-true strain curves of consolidated pure Al and different Al/AMG composites.

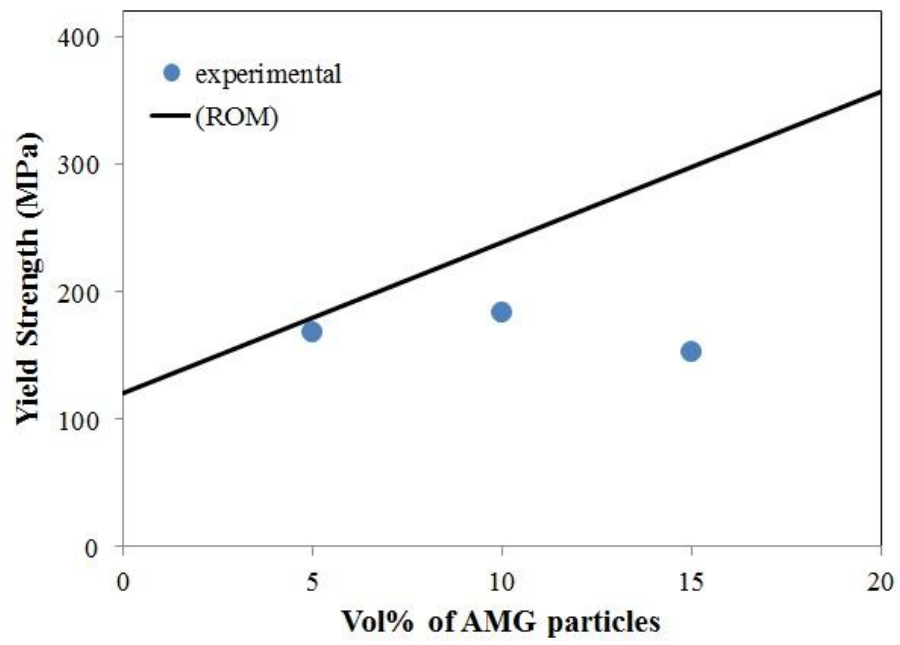

Fig. 10. Experimental yield strength and calculated values obtained from the rule of mixtures (ROM). 